\title{
Cost-effectiveness of depression case management in small practices*
}

Jochen Gensichen, ${ }^{* *}$ Juliana J. Petersen,** Michael Von Korff, Dirk Heider, Steffen Baron, Jochem König, Antje Freytag, Christian Krauth, Ferdinand M. Gerlach and Hans-Helmut König

\section{Background}

Case management undertaken by healthcare assistants in small primary care practices is effective in improving depression symptoms and adherence in patients with major depression.

\section{Aims}

To evaluate the cost-effectiveness of depression case management by healthcare assistants in small primary care practices.

\section{Method}

Cost-effectiveness analysis on the basis of a pragmatic randomised controlled trial (2005-2008): practice-based healthcare assistants in 74 practices provided case management to 562 patients with major depression over 1 year. Our primary outcome was the incremental costeffectiveness ratio (ICER) calculated as the ratio of differences in mean costs and mean number of qualityadjusted life-years (QALYS). Our secondary outcome was the mean depression-free days (DFDS) between the intervention and control group at 24-month follow-up. The study was registered at the International Standard Randomised Controlled Trial Number Registry: ISRCTN66386086.

\section{Results}

Intervention $v$. control group: no significant difference in QALYS; significantly more DFDs (mean: 373 v. 311, $P<0.01$ ); no significant difference in mean direct healthcare costs (€4495 V. €3506, $P=0.16$ ); considerably lower mean indirect costs ( $€ 5228 \mathrm{~V}$. $€ 7539, P=0.06$ ), resulting in lower total costs (€9723 $v . € 11045, P=0.41)$. The point estimate for the cost-utility ratio was $€ 38429$ per QALY gained if only direct costs were considered, and 'dominance' of the intervention if total costs were considered. Yet, regardless of decision makers' willingness to pay per QALY, the probability of the intervention being cost-effective was never above $90 \%$.

\section{Conclusions}

In small primary care practices, 1 year of case management did not increase the number of QALYS but it did increase the number of DFDs. The intervention was likely to be cost-effective.

\section{Declaration of interest}

None.
Depression causes a high global disease burden. ${ }^{1}$ In Europe, the total annual cost of depression was estimated at $€ 118$ billion in $2004 .^{2}$ The majority of patients with depression are treated in primary care settings. ${ }^{3}$ A large amount of evidence shows that collaborative care in these settings is effective in reducing depression symptoms, ${ }^{4}$ while also being cost-effective. ${ }^{5}$ In Germany, more than $50 \%$ of primary care practices are solo physician practices with limited resources, ${ }^{6,7}$ where extensive collaborative models would be difficult to implement. Primary care practices located in rural areas often have limited access to mental health specialists. In view of these challenges, non-medical healthcare professionals may be a cost-effective resource for depression management in typical primary care settings. ${ }^{7}$ Rost et al showed that nurse assistants can successfully take part in multifaceted depression quality improvement programmes in a primary care setting. ${ }^{8}$ Hunkeler et al trained nurse assistants in a depression management programme from an integrated health maintenance organisation. ${ }^{9}$ Klinkman et al showed the long-term effects of a multifaceted intervention for patients with chronic depression. ${ }^{10}$ In Germany, healthcare assistants are not as well-qualified as physician assistants or nurse assistants, ${ }^{11}$ since they only receive 2 years of basic vocational training ( 1 day of lectures per week). They generally perform administrative tasks and basic medical care, and work in primary care settings. A

*This paper was presented in an oral presentation at the 46th Congress of the German College of General Practitioners and Family Physicians in Salzburg, Austria, on 22-24 September 2011 and by poster at the European Conference on Health Economics (ECHE) in Zurich, Switzerland, on 18-21 July 2012.

${ }^{* *}$ These authors contributed equally to the work. healthcare assistant can earn between $€ 19400$ /year (3 years of professional experience) and $€ 32000 /$ year (more than 30 years of experience). ${ }^{12}$ We have already shown that depression case management provided by healthcare assistants in small, private primary care practices over a 12 -month period is effective in improving symptoms and the process of care among patients with major depression ${ }^{13}$ and here we evaluate the cost-effectiveness of this intervention.

\section{Method}

\section{Study design and participants}

We designed a pragmatic cluster-randomised controlled trial with the primary care practice as the unit of randomisation in order to avoid potential contamination (trail registration: ISRCTN66386086). The study took place in central Germany between 2005 and 2008. We assessed patients at baseline, and after 6, 12 and 24 months. The intervention lasted 12 months (between baseline and the 12-month assessment). Details on the methods employed in the trial have been published elsewhere. ${ }^{13}$ The institutional review board of Goethe University Frankfurt am Main, Germany, approved the study protocol on 25 April 2005. We used written consent procedures for general practitioners (GPs) and patients.

\section{Intervention}

We designed our case management intervention in accordance with the chronic care model, which emphasises proactive support for the patient by the entire practice team. ${ }^{14}$ Primary care 
practice-based healthcare assistants, trained as depression case managers during a 2-day workshop, contacted their patients by telephone once a month for 1 year. They monitored symptoms of depression using a structured questionnaire and supported medication adherence. They also encouraged patients to undertake pleasant activities. The assistants then reported the results of the call to the GP in a structured manner, stratifying the urgency of contact in terms of symptom severity. This intervention was provided in addition to usual care. Patients in the control group received usual care.

\section{Data collection}

At each study assessment, patients completed the Patient Health Questionnaire-9 (PHQ-9), ${ }^{13}$ a 9-item questionnaire on depressive symptoms, as well as the EQ-5D. ${ }^{15}$ The EQ-5D is a simple questionnaire for the subjective description of perceived state of health. It also provides a preference-based utility score (EQ-5D index) for each of the EQ-5D health states with the best state (perfect health) and 'death' being assigned values of 1 and 0 , respectively. ${ }^{16}$ In addition, patients completed a questionnaire on healthcare utilisation (including psychiatric in-patient care, out-patient care provided by psychologists, psychiatrists and family doctors/GPs as well as antidepressant drug use) and lost work days in the 12 months preceding the interview. Additional utilisation data were collected from the patients' medical records. Thirteen intervention practices were randomly selected to assess intervention costs using a structured questionnaire.

\section{Data analysis}

Following the concept of cost-utility analysis ${ }^{17}$ we calculated quality-adjusted life-years (QALYs) as the primary outcome to measure health effects over 24 months. To calculate QALYs we used health state utilities based on the EQ-5D index provided by Dolan. ${ }^{16}$ Depression-free days (DFDs) were calculated for our secondary outcome, using the method of Lave et al: ${ }^{18}$ if patients had a PHQ-9 score of $\geqslant 15$, they were assumed to have 'full' depression ( $100 \%$ depression or $0 \%$ DFDs); when scoring $\leqslant 4$ they were assumed to have no depression ( $0 \%$ depression or $100 \%$ DFDs); if they scored between 4 and 15, the DFDs were weighted proportionately using linear interpolation. The QALYs (DFDs) were calculated by multiplying the arithmetic average of EQ-5D index scores (DFD scores) from two neighbouring measurement points by the time period between these measurement points; in other words, we calculated the area under the curve of linearly interpolated EQ-5D index scores (DFD scores) over time. To calculate direct healthcare costs from a societal perspective, we assigned monetary values to patient care according to a German guideline ${ }^{19}$ and adjusted for inflation based on the year 2006. Using our measure, the costs of a visit to a primary care physician was $€ 17.28$, to a psychiatrist $€ 29.65$, a psychotherapist session was $€ 50.29$ and a psychiatric in-patient hospital day cost $€ 240.31$. The costs of prescribed antidepressant drugs were based on defined daily doses using unit costs from a national drug database. ${ }^{20}$ Almost all intervention costs resulted from time being spent by primary care physicians (€54.42 per hour) and healthcare assistants/case managers ( $€ 18.34$ per hour). ${ }^{21}$ Indirect costs due to lost work days of the patients were valued at $€ 90.67$ per day ${ }^{21}$ following the human capital approach. The price year used was 2006 . We did not apply discounting since the study's follow-up period was only 2 years. Discounting costs and effects hardly affected the results. The incremental cost-effectiveness ratio (ICER) was calculated as the ratio of differences in mean costs and mean number of QALYs or DFDs, respectively, between the intervention group and the control group at the 24-month follow-up. Differences in means were analysed using non-parametric bootstrapping (4000 replications) to take into account the skewed distribution of cost and effectiveness data. To visualise the statistical uncertainty of the ICER, cost-effectiveness acceptability curves were constructed using a net-benefit regression approach with bootstrap corrected standard errors (1000 replications). ${ }^{22}$

Data analysis was based on patients for whom information was available from baseline and at least one follow-up assessment. Within this sample, missing values were replaced using the last-observation-carried-forward method. The rate of missing values on the EQ-5D varied between 1 and $6 \%$. On the PHQ-9 the missing value rate varied between 0.3 and $5 \%$ and tended to be higher in the intervention group during the follow-up. We used LOCF for both costs and outcomes. Data analysis was performed with the Stata software package (Release 10) for Windows, applying an $\alpha=0.05$ level of significance.

\section{Results}

We enrolled 74 primary care practices and 626 patients at baseline (310 in the intervention group and 316 in the control group). Most primary care practices were run by only one or two GPs. After 24 months, $439(70.1 \%)$ patients (209 in the intervention group and 230 in the control group) in 71 practices could be assessed. For 562 patients (268 in the intervention group, 294 in the control group) data were available from baseline and at least one follow-up assessment. This sample was used for the analysis (Table 1).

\section{Depression outcome and utilities}

There was no significant difference in EQ-5D index scores, and thus QALYs, between the intervention and the control group. But at the 24-month follow-up, the intervention group had experienced a statistically significant, higher number of DFDs than the control group (373 v. 311, $P<0.01$ ). The mean PHQ-9 scores of the intervention group were lower after 6 months (11.9 v. 13.2, $P=0.007)$ and 12 months (10.7 v. 12.1, $P=0.009$ ). After 24 months a difference between the groups was still apparent, but was not statistically significant $(10.5$ v. $11.5, P=0.085)$.

\section{Resource use and costs}

During the 24-month follow-up period patients in the intervention group tended to spend more days in psychiatric in-patient care and missed fewer work days than patients in the control group (Table 2). The annual intervention costs were $€ 276$ per patient (Table 3), as reported elsewhere. ${ }^{23}$ During the 24 -month follow-up period there was no statistically significant difference between the two groups with regard to the mean direct costs ( 44495 v. $€ 3506, P=0.16$ ), nor with regard to the various categories of direct costs (Table 3). Mean indirect costs were considerably lower in the intervention group (€5228 v. €7539, $P=0.06$ ), resulting in lower mean total (direct + indirect) costs (€9723 v. $€ 11045, P=0.41$ ). Yet these differences were not statistically significant either.

\section{Cost-effectiveness}

The point estimate for the cost-utility ratio was $€ 38489$ per QALY gained (which corresponds to $£ 31127$ per QALY gained on the basis of an exchange rate on 31 December 2006 of $€ 1=\mathfrak{E} 0.81$ ) if only direct costs were considered, and the 'dominance' of the 


\begin{tabular}{|c|c|c|}
\hline Characteristics & $\begin{array}{l}\text { Intervention } \\
\text { group }\end{array}$ & $\begin{array}{l}\text { Control } \\
\text { group }\end{array}$ \\
\hline Participating practices, $n$ & 35 & 39 \\
\hline Maximum of two clinicians, $n(\%)$ & 35 (100.0) & $36(92.3)$ \\
\hline Female clinicians, $n$ (\%) & $16(46)$ & $17(44)$ \\
\hline Years at this practice, mean (s.d.) & $13.3(9.2)$ & $10.7(7.7)$ \\
\hline Years of job experience of healthcare & & \\
\hline assistants, mean (s.d.) & $17.3(11.2)$ & $18.8(10.3)$ \\
\hline Location, $n$ (\%) & & \\
\hline Urban $^{\mathrm{a}}$ & $23(66)$ & $21(54)$ \\
\hline Rural & $12(34)$ & $18(46)$ \\
\hline Number of patients per 3 months, ${ }^{b}$ & & \\
\hline mean (s.d.) & $1065(427)$ & $1051(435)$ \\
\hline Age of patient population at practice, $\%$ & & \\
\hline$<18$ years & 13.7 & 12.6 \\
\hline $18-65$ years & 51.7 & 56.3 \\
\hline$>65$ years & 36.0 & 31.1 \\
\hline Participating patients, $n^{c}$ & 268 & 294 \\
\hline Age in years, mean (s.d.) & $52.8(14.0)$ & $51.2(14.4)$ \\
\hline Female, $n(\%)$ & $201(75.0)$ & $230(78.2)$ \\
\hline Married, $n(\%)$ & $153(57.1)$ & $152(51.7)$ \\
\hline Employed, $n$ (\%) & $119(44.4)$ & $143(50.7)$ \\
\hline Depression, PHQ-9 score: mean (s.d.) & $17.3(3.6)$ & $17.3(3.5)$ \\
\hline \multicolumn{3}{|c|}{$\begin{array}{l}\text { a. Refers to a town with }>50000 \text { inhabitants. } \\
\text { b. In Germany, panel size is given as the number of patient registrations in a practice } \\
\text { in } 3 \text { months. } \\
\text { c. Refers to participants ( } n=562 \text { ) for whom information was available at baseline } \\
\text { and at least } 1 \text { follow-up assessment. }\end{array}$} \\
\hline
\end{tabular}

intervention if total costs were considered (Table 3). Yet, regardless of decision makers' willingness to pay per QALY, the probability of the intervention being cost-effective was never above $90 \%$ (Fig. 1). When only direct costs were taken into account, the point estimate for the ICER of the intervention was $€ 16$ per DFD. When total costs were considered, the intervention was less costly, resulting in the 'dominance' of the intervention (i.e. it being less costly and more effective). If decision makers were willing to pay $€ 10$,
Table 2 Mean resource use and work-loss days during 24-month follow-up

\begin{tabular}{|lcc|} 
& \multicolumn{2}{c|}{ Mean (s.d.) } \\
\cline { 2 - 3 } & $\begin{array}{c}\text { Intervention } \\
\text { group } \\
(n=268)\end{array}$ & $\begin{array}{c}\text { Control } \\
\text { Rroup } \\
(n=294)\end{array}$ \\
\hline Days in psychiatric in-patient care & $10.33(34.26)$ & $6.87(23.68)$ \\
\hline $\begin{array}{l}\text { Visits to out-patient physicians } \\
\text { (excluding psychiatrist) }\end{array}$ & $29.64(27.63)$ & $29.10(22.42)$ \\
\hline Visits to out-patient psychiatrist & $3.63(7.31)$ & $3.42(6.31)$ \\
\hline Visits to out-patient psychologist & $14.43(30.32)$ & $17.32(37.20)$ \\
\hline $\begin{array}{l}\text { Daily defined doses of antidepressant } \\
\text { drugs, per day }\end{array}$ & $1.07(1.15)$ & $1.04(1.16)$ \\
\hline Work-loss days & $57.66(125.18)$ & $83.14(179.38)$ \\
\hline
\end{tabular}

$€ 50$ or $€ 100$ per DFD, the respective probabilities of the intervention being cost-effective would be $31.1 \%, 93.3 \%$ or $98.3 \%$ (when only direct costs were considered), and $88.7 \%, 98.4 \%$ or 99.5\% (when total costs were taken into account). We estimated a $90 \%$ probability that the intervention would be cost-effective, if decision makers were willing to pay $€ 12$ per DFD.

\section{Discussion}

Although most research has examined academic or integrated settings as in health maintenance organisations, ${ }^{24}$ this study highlights the benefits of a low-intensity intervention in small, private primary care practices with limited resources. This trial indicates that the involvement of healthcare assistants in the care of patients with depression may be a cost-effective resource for small primary care settings. This is noteworthy, since the need for cost-effective healthcare interventions in primary care settings is increasing, and healthcare assistants (who have limited training) are employed in the majority of small primary care practices.

\section{Table 3 Mean costs, mean number of depression-free days and incremental cost-effectiveness ratio (ICER) during 24-month} follow-up a

\begin{tabular}{|c|c|c|c|c|c|}
\hline & $\begin{array}{l}\text { Intervention group, } \\
\text { mean (s.d.) } \\
\quad(n=268)\end{array}$ & $\begin{array}{l}\text { Control group, mean } \\
\text { (s.d.) } \\
(n=294)\end{array}$ & $\begin{array}{l}\text { Difference } \\
\text { Mean (s.e.) }\end{array}$ & $P$ & Point estimate \\
\hline Direct costs in $€$ & $4495.26(8490.79)$ & $3506.30(6885.68)$ & $988.96(703.16)$ & 0.16 & \\
\hline Psychiatric in-patient care & $2482.23(8233.17)$ & $1651.44(5691.01)$ & $830.80(601.71)$ & 0.20 & \\
\hline Out-patient physician (excluding psychiatrist) & $512.14(477.52)$ & $502.78(387.46)$ & $9.36(61.63)$ & 0.88 & \\
\hline Out-patient psychiatrist & $107.73(216.88)$ & $101.32(187.08)$ & $6.41(20.17)$ & 0.75 & \\
\hline Out-patient psychologist & $725.43(1525.02)$ & $870.88(1870.90)$ & $-145.44(173.36)$ & 0.40 & \\
\hline $\begin{array}{l}\text { Pharmaceuticals } \\
\text { Intervention costs }\end{array}$ & $\begin{array}{l}392.06(418.67) \\
276(-)\end{array}$ & $379.89(423.10)$ & $12.17(43.68)$ & 0.78 & \\
\hline Indirect costs in € & $5227.88(11349.82)$ & $7538.68(16264.15)$ & $-2310.80(1240.20)$ & 0.06 & \\
\hline Total costs (direct and indirect) in $€$ & $9723.14(16212.95)$ & $11044.98(18920.81)$ & $-1321.84(1591.71)$ & 0.41 & \\
\hline Depression-free days (DFDS) & $372.67(215.56)$ & $310.66(216.49)$ & $62.01(22.34)$ & 0.01 & \\
\hline Quality-adjusted life-years (QALYS) ${ }^{b}$ & $1.07(0.54)$ & $1.05(0.56)$ & $0.02(0.05)$ & 0.66 & \\
\hline $\begin{array}{l}\text { ICER of intervention for DFDS } \\
\text { Based on direct costs, € per DFDs } \\
\text { Based on total costs (direct and indirect) }\end{array}$ & & & & & $\begin{array}{c}15.95 \\
\text { Dominant }^{\mathrm{C}}\end{array}$ \\
\hline $\begin{array}{l}\text { ICER of intervention for QALYS } \\
\text { Based on direct costs, } € \text { per QALY } \\
\text { Based on total costs (direct and indirect) }\end{array}$ & & & & & $\begin{array}{c}38428.99 \\
\text { Dominant }^{\mathrm{d}}\end{array}$ \\
\hline \multicolumn{6}{|c|}{$\begin{array}{l}\text { a. Standard error (s.e.) and } P \text { for test of difference in means between intervention and control group are based on non-parametric bootstrapping with } 4000 \text { replications taking into } \\
\text { account clusters. } \\
\text { b. Based on } n=255 \text { observations in intervention group and } n=278 \text { observations in control group due to missing values for EQ-5D index (QALYS). } \\
\text { c. The intervention was associated with lower mean costs and higher mean depression-free days. } \\
\text { d. The intervention was associated with lower mean costs and more QALYS. }\end{array}$} \\
\hline
\end{tabular}




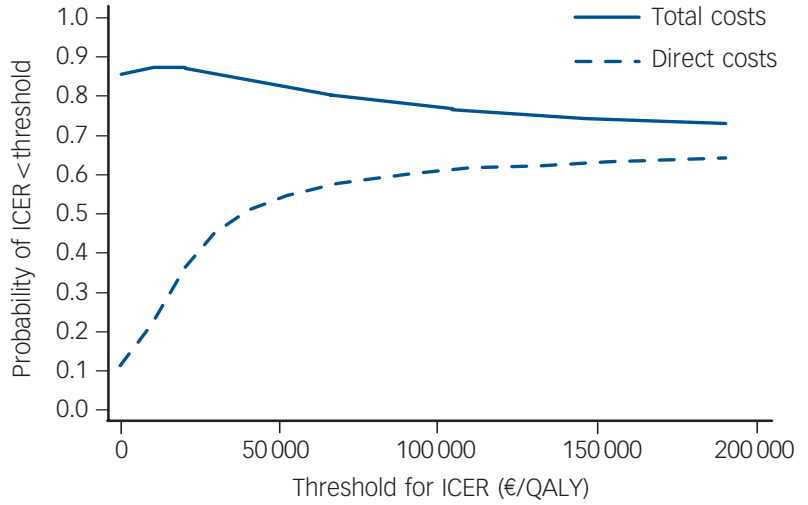

Fig. 1 Cost-effectiveness acceptability curves for direct and total costs.

Underlying regression models were bootstrapped with 1000 replications. Cluster structure of the data was taken into account. ICER, incremental cost-effectivenes ratio; QALY, quality-adjusted life-years.

\section{Comparison with findings from other studies}

Comparison of our results with cost-effectiveness studies of other - mostly more complex - collaborative care interventions for depression conducted in the USA ${ }^{25-33}$ is limited because of differences in healthcare systems and included cost categories. However, it is noteworthy that our rather simple model is the first collaborative care intervention in which dominance over usual care could be shown with regard to both costs per DFD and costs per QALY. This is mainly because of the reduction in indirect costs, which has not been included in any of the existing studies. Indirect costs are mainly attributable to lost work days, which is a relevant measure for working patients (about two-thirds in our study sample). Because of the close agreement with claims data that can be shown for the collection of data on resource utilisation by patients with mental illness via telephone interview, we assume that the collection of lost work days by patients with mental illness via personal interviews should be of sufficient quality. ${ }^{34}$

When our cost data were converted to US dollar purchasing power parities and those of other studies are de-/inflated to the year 2006 to facilitate comparison, we found two other studies reporting lower direct costs per DFD than our study. Katon et $a l^{25}$ evaluated the IMPACT intervention, which focused on elderly patients and is based on a case manager who follows up the patient by telephone, coordinates antidepressant therapy and performs a 6- to 8-session psychotherapy programme, if necessary. Liu et $a l^{26}$ evaluated a team-based intervention incorporating a clinical psychologist, a psychiatrist, a social worker and a psychology technician. The intervention comprised diagnosis, treatment, patient education, patient support and progress evaluation. The more favourable ICER of these more complex interventions was as a result of greater effects (gain of 107 DFDs over 24 months) in the case of Katon et al and very low incremental costs for a gain of 15 DFDs over 9 months in the case of Liu et al. Direct costs per DFD similar to our study were reported by Rost et $a l^{27}$ who evaluated a management programme focusing on the encouragement of patients to follow a guideline-concordant therapy and on its maintenance, and by Simon et $a l^{28}$ who analysed a relapse prevention programme consisting of patient education and frequent visits, telephone and mail contacts. Rost et al showed a gain of 59 DFDs over 24 months whereas Simon et al found a gain of 14 DFDs over 12 months. The direct costs per DFD reported by three further studies ${ }^{29-31}$ were nearly twice as high as in our study.

Direct costs per QALY have been reported for six collaborative care interventions. Three of these interventions lead to more favourable ICERs than in our study, ${ }^{25,27,32}$ one had an ICER comparable with our results, ${ }^{31}$ and two had less favourable ICERs. ${ }^{31,33}$ The studies showing more favourable ICERs reported a QALY gain more than twice as high as found in our study.

\section{Using DFDs as a measure}

With regard to the difference of 62 DFDs between the groups over 24 months, we did not expect larger effects since the intervention was in addition to regular primary care and, unlike other trials, did not make use of expensive psychiatrist or psychologist contacts. ${ }^{35}$ Case management seemed to improve the symptoms of depression during its 12 months' duration. One year after the end of the case management intervention, the effect was still apparent, but was not statistically significant. From a clinical point of view it may therefore be beneficial to the patient to extend the duration of this low-intensity, low-cost intervention, as has recently been suggested. ${ }^{10}$

Depression-free days represent a patient-centred approach to measurement. Patients may benefit from DFDs, since they represent additional time for pleasant and work-related activities. ${ }^{36}$ However, decision makers may assess the value of depression interventions by direct and indirect costs as well as generic outcomes such as QALYs. Naturally, health state utilities based on the generic EQ-5D quality of life instrument capture different aspects of well-being than disease-specific DFDs based on the PHQ-9. Whereas DFDs focus on depression, depression is directly addressed by only one out of five dimensions of the EQ-5D, with the other dimensions measuring problems in other domains of quality of life. As a consequence DFDs might be more responsive to changes in depressive symptoms. This might explain why the ICER based on DFDs may appear more favourable than that based on QALYs. However, it should be pointed out that there is no threshold value for acceptable cost per DFD.

Pyne et $a l^{37}$ undertook an attempt to translate DFDs into QALYs. According to the formula developed by Pyne et al the 373 DFDs in the intervention group and the 311 DFDs in the control group would translate into 1.01 and 0.94 QALYs, respectively. This would result in a difference of 0.07 QALYS between the two groups and hence a much more favourable ICER.

\section{Limitations}

Our study has several limitations. One limitation is that direct costs were restricted to the costs of psychiatric care whereas the cost of somatic care can also be influenced by depression. In addition, costs were calculated based on self-reported data of service use and work loss days, as has been done in many other cost-effectiveness analyses. Recall bias is likely to lead to an underestimation of costs. However, as both the intervention group and the control group were possibly affected by this bias, its effect on the ICER was probably small as the ICER was calculated from differences between the two groups. Moreover, due to financial constraints in the funding of the study we could not assess intervention costs in all practices.

Another limitation is the loss to follow-up over the 24-month period, which may have led to patient selection bias. However, previously calculated sensitivity analyses have shown that the effects of the intervention on the main outcome remained statistically significant and stable under unfavourable assumptions with regard to non-participation in follow-up assessments. ${ }^{13}$ The use of LOCF for both costs and effects is likely to result in a conservative estimate. This is caused by patients in the interventional group tending to withdraw earlier and more frequently. A complete-case analysis of our data (intervention group: $n=198$, 
control group: $n=216)$ resulted in larger treatment effects than those from LOCF (DFDs: $66.22 v$ v. 62.01; QALYs: $0.04 v$ v. 0.02), which supports our assumption. It also holds for the difference in the total costs between both study groups $(€-1931 v$. $€-1322$ ).

\section{Implications}

The results of this study suggest that in small primary care practices 1 year of case management may be cost-effective. After 24 months, patients who had received case management had 62 additional DFDs, although the DFD-gain did not significantly show up in a QALY gain. Since the crucial clinical effect seems to occur during the intervention period, it may be beneficial if patients receive this low-cost intervention for longer than 12 months. The active involvement of practice-based healthcare assistants in patient care may improve depression care at economically justifiable costs.

\footnotetext{
Jochen Gensichen, MD, MPH, MSc, Institute of General Practice and Family Medicine, Jena University Hospital, Jena and Institute of General Practice, GoetheUniversity Frankfurt am Main, Germany; Juliana J. Petersen, MD, MPH, Institute of General Practice, Goethe-University Frankfurt am Main, Germany; Michael Von Korff, SCD, Group Health Research Institute, Seattle, USA; Dirk Heider, MSC, Department of Medical Sociology and Health Economics, Hamburg Center for Health Economics, University Medical Center Hamburg-Eppendorf and Institute of Social Medicine, Occupational Health and Public Health, University of Leipzig Germany; Steffen Baron, $\mathrm{MD}$, Institute of General Practice, Goethe University Frankfurt am Stefen Baron, $M$ Dönig $S C D$, I (1) Epidemiology and Informatics, University Mainz, Germany; Antje Freytag, SCD, Institute of Genera Practice and Family Medicine, Jena University Hospital, Jena, Germany; Christian Krauth, SCD, Medical School Hannover, Germany; Ferdinand M. Gerlach, MD, MPH, Institute of General Practice, Goethe-University Frankfurt am Main, Germany; Hans-Helmut König, MD, MPH, Department of Medical Sociology and Health Economics, Hamburg Center for Health Economics, University Medical Center Hamburg-Eppendorf, Germany

Correspondence: Jochen Gensichen, MD, MA, MPH, Institute of General Practice and Family Medicine, Friedrich-Schiller-University/Jena University Hospital, Bachstr. 18, D-07743 Jena, Germany. Email: jochen.gensichen@ med.uni-jena.de

First received 25 Jul 2012, final revision 14 Dec 2012, accepted 8 Jan 2013
}

\section{Funding}

Exclusive public funding for the Primary care Monitoring for depressive Patients Tria (PROMPT) came from the German Ministry of Education and Research (numbers: 01GK0302 and 01GK0702). The Study was awarded the Dr. Lothar Beyer Award/German Primary Care Research Award 2008

\section{References}

1 Üstün TB, Ayuso-Mateos JL, Chatterji S, Mathers C, Murray CJL. Global burden of depressive disorders in the year 2000. Br J Psychiatry 2004; 184: 386-92.

2 Sobocki $\mathrm{P}$, Jonsson B, Angst J, Rehnberg C. Cost of depression in Europe. J Ment Health Policy Econ 2006; 9: 87-98.

3 Thielke $S$, Vannoy $S$, Unutzer J. Integrating mental health and primary care. Prim Care 2007; 34: 571-92.

4 Gilbody S, Bower P, Fletcher J, Richards D, Sutton AJ. Collaborative care for depression: a cumulative meta-analysis and review of longer-term outcomes. Arch Intern Med 2006; 166: 2314-21.

5 van Steenbergen-Weijenburg KM, van der Feltz-Cornelis CM, Horn EK, van Marwijk HW, Beekman AT, Rutten FF, et al. Cost-effectiveness of collaborative care for the treatment of major depressive disorder in primary care. A systematic review. BMC Health Serv Res 2010; 10: 19

6 Kassenärztliche Bundesvereinigung (KBV). [National Association of Statutory Health Insurance Physicians]. Basic data 2010/2011 on SHI-authorised physician care in Germany [in German]. KBV, 2012 (http://www.kbv.de/ publikationen/125.html).

7 Bodenheimer T, Laing BY. The teamlet model of primary care. Ann Fam Med 2007; 5: 457-61.

8 Rost K, Nutting P, Smith J, Werner J, Duan N. Improving depression outcomes in community primary care practice: a randomized trial of the quEST intervention. Quality enhancement by strategic teaming. J Gen Intern Med 2001; 16: 143-9.

9 Hunkeler EM, Meresman JF, Hargreaves WA, Fireman B, Berman WH, Kirsch AJ, et al. Efficacy of nurse telehealth care and peer support in augmenting treatment of depression in primary care. Arch Fam Med 2000; 9: $700-8$.

10 Klinkman MS, Bauroth S, Fedewa S, Kerber K, Kuebler J, Adman T, et al. Long-term clinical outcomes of care management for chronically depressed primary care patients: a report from the depression in primary care project. Ann Fam Med 2010; 8: 387-96.

11 Bosley S, Dale J. Healthcare assistants in general practice: practical and conceptual issues of skill-mix change. Br J Gen Pract 2008; 58: 118-24.

12 German Medical Association. Collective Agreements, Collective Bargaining Agreement, Collective Bargaining for Occupational Retirement Provision and Fee Agreement for Health Care Assistants/Medical Assistents [in German]. German Medical Association, 2011 (http://www.bundesaerztekammer.de/ page. asp?his = 1.99.3478.3860.3869)

13 Gensichen J, von Korff M, Muth C, Peitz V, Beyer M, Guethlin C, et al. Case management for depression by health care assistants in small primary care practices - a cluster randomized trial. Ann Intern Med 2009; 151: $369-80$.

14 Wagner EH, Austin BT, Davis C, Hindmarsh M, Schaefer J, Bonomi A. Improving chronic illness care: translating evidence into action. Health Aff (Millwood) 2001; 20: 64-78.

15 The EuroQol Group. Euro-Qol - a new facility for the measurement of health-related quality of live. Health Policy 1990; 16: 199-208.

16 Dolan P. Modeling valuations for EuroQol health states. Med Care 1997; 35: 1095-108

17 Drummond MF, Sculpher MJ, Torrance GW, O'Brien BJ, Stoddart GL. Methods for the Economic Evaluation of Health Care Programmes. Oxford University Press, 2005.

18 Lave JR, Frank RG, Schulberg HC, Kamlet MS. Cost-effectiveness of treatments for major depression in primary care practice. Arch Gen Psychiatry 1998; 55: 645-51.

19 Krauth C, Hessel F, Hansmeier T, Wasem J, Seitz R, Schweikert B. Empirical standard costs for health economic evaluation in Germany - a proposal by the working group methods in health economic evaluation [in German]. Gesundheitsw 2005; 67: 736-46.

20 Wissenschaftliches Institut der AOK [AOK Research Institute]. ATC classification with daily doses. Official version of the ATC-index with DDD information for Germany in the year 2006 [in German]. DIMDI, 2006 (http://www.wido.de/fileadmin/wido/downloads/pdf_arzneimittel/wido arz_amtl_atc-index_0106.pdf).

21 Federal Statistical Office Germany. Structure of Earnings Survey 2006 Earnings by Professions. Earnings and Labour Cost [in German]. Federal Statistical Office Germany, 2008.

22 Hoch JS, Rockx MA, Krahn AD. Using the net benefit regression framework to construct cost-effectiveness acceptability curves: an example using data from a trial of external loop recorders versus Holter monitoring for ambulatory monitoring of "community acquired" syncope. BMC Health Serv Res 2006; 6: 68

23 Baron S, Heider D, Gensichen J, Petersen JJ, Gerlach FM, Krauth C, et al. Cost structure of a telephone-based case management in primary care depression therapy [in German]. Psychiatr Prax 2011; 38: 342-4.

24 Williams Jr JW, Gerrity M, Holsinger T, Dobscha S, Gaynes B, Dietrich A. Systematic review of multifaceted interventions to improve depression care. Gen Hosp Psychiatry 2007; 29: 91-116.

25 Katon WJ, Schoenbaum M, Fan MY, Callahan CM, Williams Jr J, Hunkeler E, et al. Cost-effectiveness of improving primary care treatment of late-life depression. Arch Gen Psychiatry 2005; 62: 1313-20.

26 Liu CF, Hedrick SC, Chaney EF, Heagerty P, Felker B, Hasenberg N, et al. Cost-effectiveness of collaborative care for depression in a primary care veteran population. Psychiatr Serv 2003; 54: 698-704.

27 Rost K, Pyne JM, Dickinson LM, LoSasso AT. Cost-effectiveness of enhancing primary care depression management on an ongoing basis. Ann Fam Med 2005; 3: 7-14.

28 Simon GE, Von Korff M, Ludman EJ, Katon WJ, Rutter C, Unutzer J, et al. Cost-effectiveness of a program to prevent depression relapse in primary care. Med Care 2002; 40: 941-50.

29 Simon GE, Katon WJ, VonKorff M, Unutzer J, Lin EH, Walker EA, et al. Cost-effectiveness of a collaborative care program for primary care patients with persistent depression. Am J Psychiatry 2001; 158: 1638-44.

30 Simon GE, Manning WG, Katzelnick DJ, Pearson SD, Henk HJ, Helstad CS Cost-effectiveness of systematic depression treatment for high utilizers of general medical care. Arch Gen Psychiatry 2001; 58: 181-7. 
31 Schoenbaum M, Unutzer J, Sherbourne C, Duan N, Rubenstein LV, Miranda J, et al. Cost-effectiveness of practice-initiated quality improvement for depression: results of a randomized controlled trial. JAMA 2001; 286: 1325-30.

32 Pyne JM, Rost KM, Zhang M, Williams DK, Smith J, Fortney J. Costeffectiveness of a primary care depression intervention. J Gen Intern Med 2003; 18: 432-41.

33 Pyne JM, Fortney JC, Tripathi SP, Maciejewski ML, Edlund MJ, Williams DK. Cost-effectiveness analysis of a rural telemedicine collaborative care intervention for depression. Arch Gen Psychiatry 2010; 67: 812-21.

34 Heinrich S, Deister A, Birker T, Hierholzer C, Weigelt I, Zeichner D, et al. Accuracy of self-reports of mental health care utilization and calculated costs compared to hospital records. Psychiatry Res 2011; 185: 261-8.

35 Simon GE, Katon WJ, Lin EH, Rutter C, Manning WG, Von Korff M, et al. Cost-effectiveness of systematic depression treatment among people with diabetes mellitus. Arch Gen Psychiatry 2007; 64: 65-72.

36 Ludman E, Katon W, Bush T, Rutter C, Lin E, Simon G, et al. Behavioura factors associated with symptom outcomes in a primary care-based depression prevention intervention trial. Psychol Med 2003; 33: 1061-70.

37 Pyne JM, Tripathi S, Williams DK, Fortney J. Depression-free day to utility-weighted score: is it valid? Med Care 2007; 45: 357-62.

\section{poem}

\section{Abandoned}

\section{Bear Loveday Tyler}

my white bird

flew away this morning

taking the windowlatch in her beak like

a sprig of olive

my yellow flower

died this morning

drooping over the vase

shedding petals like

a may shower

my green hills

crumbled this morning

taking my window through

shades of darkness like

the hand of a one-night lover

my brown ivy fled this morning

taking with him

my white bird

my yellow flower

my green hills

now I am left with red of passion and blue of pathos

neither of which is mine

sunset

and the rainbow

rises

soon

This poem is from Bear Loveday Tyler's book Love Grenade, published by Survivors' Poetry in 2006. Loveday was mentored by Robin Ford. Another of her poems, So This Is Death, was published in the Journal in September 2012.

Chosen by Femi Oyebode. 